majority of them would not pass the examination with ease.

Criticism of the Joint Consultants Committee is not new. Over the years it has worked hard and well for hospital doctors, as the results of its labours have shown. But only occasionally has the medical world been given a glimpseusually by way of a prepared statement - of what the committee thinks and why. Thus it was vulnerable to attack from regional consultants, and a motion asking for greater representation for them on the Joint Consultants Committee was narrowly defeated. The B.M.A.'s Central Committee for Hospital Medical Services is now the negotiating body for hospital doctors' terms and conditions of service, and it is on this committee that the regional consultants' voice is best heard. However, the debate served a good purpose in informing representatives-for the first time for some-about the Joint Consultants Committee and its relationship to the B.M.A.

Besides its main debates on the problems of general practice, the hospitals, and the public health service the Representative Body declared its support for a voluntary ban on the prescribing of amphetamines. It considered the ethics of reporting cases of battered babies, and it saw "paper" clothing ignited to demonstrate a fire hazard. B.M.A. sponsorship of candidates for election to the G.M.C. is to cease, and there is to be an independent examination of the Association's constitution by outside experts. The Meeting also heard some forthright words from the Treasurer about the effects of inflation and the heavy cost of the recent medico-political crisis on the Association's finances and its four-year budget cycle. He warned that subscriptions might again have to go up.

1 British Medical fournal Supplement, 1970, 1, 51.

- British Medical fournal Supplement, 1970, 1, 51.

3 British Medical fournal, 1970, 3, 1.

- Royal College of Obstetricians and Gynaecologists, British Medical fournal, 1970, 2, 529.

\section{Treatment of the Nephrotic Syndrome}

The nephrotic syndrome is a combination of physical signs and biochemical abnormalities which are the direct consequence of heavy proteinuria. Symptomatic treatment is appropriate for most patients. It consists of a diet rich in protein and low in salt, together with the administration of varying combinations of diuretics and the control of hypertension. Logically, treatment should also be aimed at correcting the underlying renal disease.

Even when secondary causes of the nephrotic syndrome, such as amyloidosis, are excluded there remain at least eight different pathological lesions that may be associated with the condition. ${ }^{1}$ It is reasonable to expect that each lesion will be associated with a different prognosis and response to treatment. Thus in the present state of knowledge conclusions on the likely course of the disease should be drawn only after all attempts have been made to allocate patients to groups which are defined as precisely as possible in accordance with the histological techniques available. A possible exception to this rule may be cases in children with the typical history and findings associated with the "minimal change" lesion, especially if this diagnosis is supported by the finding of a highly selective differential protein clearance. ${ }^{2} 3$ Because of the rarity of patients with the nephrotic syndrome ${ }^{4}$ a single physician can seldom collect enough patients with a particular lesion to compare different methods of treatment, and so clinical trials must be on a collaborative basis.

Little is known about the long-term prognosis of patients with the nephrotic syndrome associated with obvious histological abnormalities. Undoubtedly some improve either spontaneously or as the result of treatment, and it is therefore worth reporting series of patients in whom follow-up has been exceptionally prolonged even though the initial histological diagnosis was, by modern standards, incomplete. A recent paper by R. B. Miller and colleagues ${ }^{5}$ indicated that, out of 38 such patients treated with steroids and followed up for an average of five years, six lost their proteinuria completely and 11 either died of renal failure or developed impaired renal function (plasma creatinine more than $2 \mathrm{mg}$. per $100 \mathrm{ml}$.).

Adrenal corticosteroids have been used to treat patients with the nephrotic syndrome for many years. Dramatic response with complete resolution of the illness is usually observed in patients with minimal renal lesions. ${ }^{6}$ In about half this result is permanent, but the remainder relapse repeatedly when the dose of steroids is reduced or they are withdrawn. Ultimately many (perhaps 20\%) of these patients $\mathrm{die}^{78}$ either from a complication arising during a relapse or from some side-effect of prolonged treatment. Morbidity may be substantial, particularly failure of growth in children and osteoporosis and hypertension in adults.

When steroids are given to patients with proliferative glomerulonephritis the results are much less impressive, and it is relatively unusual to observe complete resolution of the illness. This does not necessarily imply that treatment has been useless, as it may be argued that without it the disease would have progressed further or more rapidly. The situation is complicated by the fact that the side-effects of steroids are particularly dangerous in patients with renal disease. The protein-catabolic effects lead to an increase in muscle wasting

1 Hamburger, J., Nephrology, 1968. Philadelphia, Saunders.

2 Blainey, J. D., Brewer, D. B., Hardwicke, J., and Soothill, J. F., Quarterly Fournal of Medicine, 1960, 29, 235.

3 Cameron, J. S., British Medical fournal, 1968, 4, 352.

Sharpstone, P., Ogg, C. S., and Cameron, J. S., British Medical fournal,

1969,2 , 533 .
5 Miller, R. B., Harrington, J. T., Ramos, C. P., Relman, A. S., and Schwartz, W. B., American fournal of Medicine, 1969, 46, 919.

- White, R. H. R., Proceedings of the Royal Society of Medicine, 1967, 60, 1164 .

7 Cornfeld, D., and Schwartz, M. W., fournal of Pediatrics, 1966, 68, 507.

8 Arneil, G. C., and Lam, C. N., Lancet, 1966, 2, 819.

Rose, G., and Black, D. A. K., Quarterly Fournal of Medicine, 1967, 36,

10 Soyka, L. F., and Saxena, K. M., Journal of the American Medical Association, 1965, 192, 225.

11 Friedman, M., and Strang, L. B., Lancet, 1966, 2, 568.

12 White, R. H. R., Cameron, J. S., and Trounce, J. R., British Medical Fournal, 1966, 2, 853.

13 Ettledorf, J. N., Roy, S., Summitt, R. L., Sweeney, M. J., Wall, H. P., and Berton, W. M., fournal of Pediatrics, 1967, 70, 758.

14 Moncrieff, M. W., White, R. H. R., Ogg, C. S., and Cameron, J. S., British Medical fournal, 1969, 1, 666 .

15 Lagrue, G., Bariéty, J., Canlorbe, P., Vassal, J., and Milliez, P., Presse Médicale, 1967, 75, 1773.

16 Abramowicz, M., et al., Lancet, 1970, 1, 959.

17 Barratt, T. M., and Soothhill, J. F., Nephron, 1970 (in press), abstract only.

8 Soothill, J. F., Proceedings of thi 4th International Congress of Nephrology, Stockholm, 1969.

19 Sharpstone, P., Ogg, C. S., and Cameron, J. S., British Medical fournal, $1969,2,535$.

20 Pollack, V. E., Rosen, S., Pirani, C. L., Muehrcke, R. C., and Kark, R. M., Annals of Internal Medicine, 1968, 69, 1171.

2 Bariéty, J., Samarcq, P., Lagrue, G., Fritel, D., and Milliez, P., Presse Médicale, $1968,76,2179$.

22 Rastogi, S. P., Hart-Mercer, J., and Kerr, D. N. S., Quarterly fournal of Medicine, 1969, 38, 335 
and in the level of blood urea, while the salt-retaining effects may aggravate the oedema and lead to hypertension. In a recent controlled trial ${ }^{9}$ of steroid treatment versus symptomatic treatment alone the early mortality was higher among the patients who received steroids, emphasizing that even the modest doses of steroids given were potentially dangerous. It may be argued that doses of about $20 \mathrm{mg}$. prednisolone daily serve only to suppress adrenal function and that doses of $60 \mathrm{mg}$. daily for several months are necessary to produce an effect on the renal disease. Such regimens are correspondingly more dangerous, and no controlled trial has been published that investigates their value. There is some evidence ${ }^{10}$ that the administration of a double dose of steroids on alternate days is less toxic but as efficacious, and it is reasonable to give large doses in this way. Recently $M$. Friedman and L. B. Strang ${ }^{11}$ have shown that corticotrophin (A.C.T.H.) produces less stunting of growth for a given effect than does prednisolone. However, the problems of hypertension and a cushingoid appearance remain.

Owing to the limitations of steroid therapy interesi has grown in the cytotoxic drugs. Azathioprine, ${ }^{12}$ cyclophosphamide, ${ }^{1314}$ and chlorambucil ${ }^{15}$ have all been used extensively, and there can be no doubt that cyclophosphamide and chlorambucil are helpful in the treatment of the patient with a minimal renal lesion. The value of azathioprine is less certain. M. Abramowicz and his colleagues ${ }^{16}$ concluded that, at least in children and in fairly low dosage, it was no better than a placebo. Remissions induced with cyclophosphamide last longer than those induced with steroids, ${ }^{1718}$ and many patients who were previously dependent on steroids now appear to have been cured and to require no further treatment. There is some doubt about the best therapeutic regimen. M. W. Moncrieff and his colleagues ${ }^{14}$ have induced a leucopenia (and usually alopecia) with a high initial dose and then maintained the leucopenia for about three months with a relatively small dose. On the other hand, J. F. Soothill ${ }^{17} 18$ has found that the continuous administration of an intermediate dose for two months produces a remission without inducing either leucopenia or alopecia. Relapse occasionally follows withdrawal of treatment, and in some cases it is related to inadequate therapy. ${ }^{14}$

Given to patients with proliferative glomerulonephritis, azathioprine has occasionally produced a dramatic response. ${ }^{12}$ Relatively high and dangerous doses $(4-6 \mathrm{mg} . / \mathrm{kg}$. body wt. per day) have been necessary, and recently there have been attempts to use smaller doses combined with modest doses of steroids. A small controlled trial ${ }^{19}$ of this method of treatment in adults showed slight benefit that was just significant statistically, and a much larger trial at present in progress under the supervision of the Medical Research Council has led to the same conclusion. There have been no controlled trials of cyclophosphamide in the treatment of proliferative glomerulonephritis, though occasional patients, especially children, do seem to respond.

Patients with membranous nephropathy run a downhill course over many years. During this time their proteinuria fluctuates and occasionally their urine becomes free of protein for a period. The underlying lesion persists, however, and it is generally considered that neither steroids nor cytotoxic drugs affect the course of the disease ${ }^{20}$ Occasional reports ${ }^{21}{ }^{22}$ challenge this view, and recently S. P. Rastogi and colleagues ${ }^{22}$ reported on four patients who were given prolonged courses of steroids and lost their proteinuria for periods up to 6.5 years. Repeated renal biopsies showed that the histological lesion persisted but had not progressed significantly.

\section{Pericarditis and Rheumatoid Arthritis}

Patients with systemic lupus erythematosus may present with rheumatoid arthritis, and patients with unequivocal rheumatoid disease may develop the serological changes of systemic lupus erythematosus. But the great majority of patients show the lesions of only one of these diseases, and the frequency of their overlap has been exaggerated. It is therefore surprising that little attention has been paid to the pericarditis of rheumatoid arthritis when it is so well recognized as a feature of systemic lupus erythematosus.

Necropsy studies have given an overall incidence of pericarditis in association with rheumatoid arthritis as high as $30 \%{ }^{1-3}$ and this complication is recognized in about $7 \%$ of cases of juvenile rheumatoid arthritis. ${ }^{4} \mathrm{~A}$ recent study by J. Kirk and J. Cosh of 33 patients with rheumatoid pericarditis is therefore of interest. ${ }^{5}$ The condition must be taken seriously, for acute or chronic pericardial effusion, chronic constriction, and even haemopericardium with tamponade may supervene. The pathological changes found in most cases at necropsy are obliterative pericarditis, with acute fibrinous pericarditis making up almost all the remainder. Specific granulomatous infiltration is rare; when it is present the lesions are found on the epicardial surface of the heart as small necrotic nodules similar histologically to the subcutaneous rheumatoid nodule. ${ }^{2} 3$

The onset of pericarditis seems to bear no relationship to the duration of the arthritis, though it is particularly apt to be found in middle-aged males in whom the arthritis was of acute onset. It is perhaps commoner when the arthritis is active than when it is dormant. Serological tests for rheumatoid arthritis are usually positive in patients developing pericarditis, and one-third of these patients have typical rheumatoid nodules. Anaemia and a raised erythrocyte sedimentation rate merely reflect the activity of the arthritis.

On careful inquiry a history of chest pain can be obtained in about half the patients with pericarditis. The pain is frequently pleuritic and fleeting in nature, lasting only a matter of hours or a day or so. In some the pain may closely simulate that of cardiac ischaemia, but it is distinguished by alteration in intensity with changes in posture. The remaining half of these patients have no symptoms, and the condition is diagnosed on routine clinical examination.

The characteristic auscultatory finding of a pericardial friction rub may be absent, but it is heard in most patients at some period of their illness. The rub may be atypical and may be confined to systole, making differentiation from a systolic murmur difficult. This difficulty may be increased by the persistence of the rub unchanged for several months. Lowgrade fever is frequently present and should alert the physician to seek this particular complication.

Confirmation may come from electrocardiographic changes, alteration of the cardiac outline on chest radiograph, or aspiration of pericardial fluid. The characteristic E.C.G. pattern in pericarditis is the raising of the ST segment without $T$ wave inversion. Later, abnormalities of the $T$ waves may appear, including inversion; they are found only when the

\footnotetext{
Bywaters, E. G. L., British Heart Fournal, 1950, 12, 101.

Goehrs, H. R., Baggenstoss, A. H., and Slocumb, C. H., Arthritis and Rheumatism, 1960, 3, 298.

3 Lebowitz, W. B., Annals of Internal Medicine, 1963, 58, 102.

Leitman, P. S., and Bywaters, E. G. L., Pediatrics, 1963, 32, 855.

Kirk, J., and Cosh, J., Quarterly fournal of Medicine, 1969, 152, 397.

Hart, F., British Medical fournal, 1966, 2 131.

Harrold, B. P., British Medical fournal, 1968, 1, 290.
} 